\title{
ARTICLE \\ Inlight Optically Stimulated Luminescence for Occupational Monitoring Service in Thailand.
}

\author{
Waraporn SUDCHAI and Attakovit SA-NGAN-SAT
}

Department of Medical Sciences, Thailand.

\begin{abstract}
In Thailand, Personal Radiation Monitoring Service is responsible of Department of Medical Sciences (DMSc), Ministry of Public Health, which served the personal dosimeters for nearly 30,000 radiation workers, medical industrial and research, by using TLD and OSL technology. Inlight Optically Stimulated Luminescence (OSL) technology, the modern in passive radiation protection dosimetry, is selected to replace the old film badge system in 2009. Radiation exposure is measured by stimulating the detector, aluminum oxide $\left(\mathrm{Al}_{2} \mathrm{O}_{3}: \mathrm{C}\right)$ crystal, with a green Light Emitting Diode (LED) array causing the luminescent phenomena which proportion to the amount of radiation absorbed. During the stimulation only some trapped electrons are released so the dosimeters can be reread. The dosimeters are reported to have a high sensitivity and dose can be accumulated from $10 \mu \mathrm{Sv}$ ( $1 \mathrm{mrem})$ to $10 \mathrm{~Sv}$ (1,000 rem). For photon and beta monitoring conventional Inlight OSL dosimeters are used but for neutron monitoring Inlight OSLN dosimeters are used. Dose algorithm for dose reporting in term of $\operatorname{Hp}(10), \operatorname{Hp}(0.07)$ and $\mathrm{Hp}(3)$ were accredited by NAVLAP, the accreditation body in the United State. In this study, neutron dose validation was performed by comparison method. OSLN cards were sent to irradiate with standard neutron sources at the PTB in Germany. The percentage difference between calculated dose and delivered dose were found to be $6.5 \%$ for Cf- 252 neutron source and $1 \%-37 \%$ for Am-Be neutron source respectively. For Cf- 252 neutron monitoring, built-in correction factor will be used while for Am-Be neutron monitoring calibration graph from this study will be used. By the year 2011, all of the service will be switched to OSL system.
\end{abstract}

\section{KEYWORDS: Optically stimulated luminescence, Occupational monitoring}

\section{Introduction}

The Film Badge personal radiation monitoring services has been set up at the Department of Medical Sciences (DMSc), Ministry of Public Health since 1973. In 1997, around 5,000 clients were converted to use the Harshaw TLD system. In 2009 the InLight Optically Stimulated Luminescence (OSL) from Landauer was selected to replace all 20,000 Film Badge clients. InLight OSL card composes of a slide and a plastic case shown in Figure 1 and Figure 2. Four elements of Aluminum oxide $\left(\mathrm{Al}_{2} \mathrm{O}_{3}\right.$ :C) powder sandwiched between two layer of polyester are positioned on the slide. Different thickness of $\mathrm{Al}$ and $\mathrm{Cu}$ filters were designed for $\mathrm{Hp}(10), \mathrm{Hp}(0.07)$ and $\mathrm{Hp}(3)$. Individual sensitivity or element correction coefficient (ecc) of all elements determined from a factory can be read via etched code called $2 \mathrm{D}$ slide code while the cards are identified by the bar code attached on the case.

In the luminescence process ${ }^{1)}$, the irradiated dosimeter will be stimulated by a quantum of visible green light from the Light Emitting Diode (LED). During the stimulation only some fractions of populated electrons will be depopulated. The amount of luminescence is proportional to the absorbed radiation and remain unchanged significantly after reading. This characteristic enable the OSL to be read out many times. The performance testing of the InLight OSL was performed and found to be conformed to the criteria defined by the national approval bodies ${ }^{2,3}$. Type testing of the system was also performed according to IEC $61066^{4)}$.

*Corresponding Author, Email:waraporn.s@dmsc.mail.go.th (C)2012 Atomic Energy Society of Japan, All Rights Reserved
Fading for 3 months storing period at $20{ }^{0} \mathrm{C}$ was found to be less than $1 \%$ and less than $10 \%$ at $40^{\circ} \mathrm{C}$. Lower Limit of Detection $^{3)}$ were found to be $40 \mu \mathrm{Sv}$ for 1 month and $60 \mu \mathrm{Sv}$ for 3 months .

DMSc is the national service provider. In 2011, the services are provided to approximately 30,000 radiation workers in all medical industrial and research institutes. For photon-beta users, the conventional InLight OSL are provided while the InLight OSL neutron type called OSLN are provided for the neutron users. Element 2 of the OSLN was coated with Li-6 for albedo or thermal neutron detection. The wearing period is normally 3 months but for 1 month optional for the high risk radiation workers. Two automatic 200 InLight desktop readers (Figure 3) are used. The system are calibrated with the set of Landauer calibration cards irradiated by dosimetry laboratory which is traceable to NIST. One mobile reader (Figure 4) is employed in the system for an on-site emergency analysis and for extremity dosimeters service. Computer software for reader control and dose algorithm are integrated. Neutron dose evaluation is also included in the new software version.

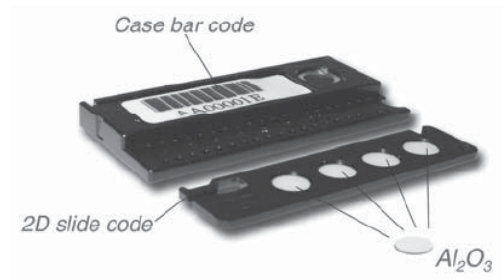

Fig. 1 InLight OSL dosimeter with slide and plastic case. 
In this study, the validation of dose evaluation was carried out by inter-laboratory comparison with PTB.

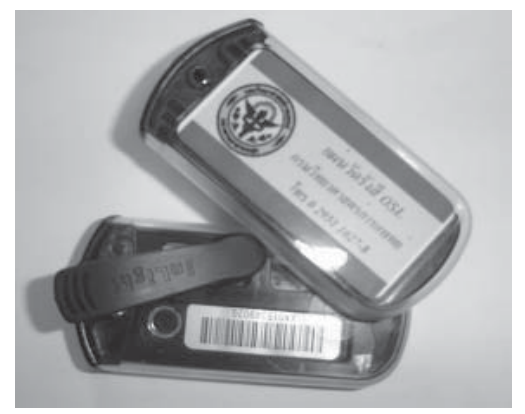

Fig. 2 Plastic cover with case and slide inside.

\section{Method}

Inlight OSLN cards were sent to irradiate at PSDL in Germany. Four cards were irradiated with Cs-137 and another fours cards with $\mathrm{D}_{2} \mathrm{O}$ Cf- 252 neutron source. The delivered $\mathrm{Hp}(10)$ dose were $2 \mathrm{mSv}$. Other OSLN cards were irradiated with Am-be neutron source. The delivered Hp(10) dose were between 1-4 mSv. Irradiations were performed on PMMA slab phantom at 1 meter under temperature and pressure control condition.

All irradiated and controlled cards were read and evaluated dose. Software built in correction factors ${ }^{5)}$ were automatically applied for Cs-137 and Cf-252. But for Am Be, user need to specify neutron energy to get an additional correction factor. Percentage difference between Delivered and Calculated dose were compared. For Am-Be dose, calibration graph between neutron dose from software calculation and PSDL delivered dose was plotted.

\section{Result}

Delivered and calculated dose as well as percentage difference were shown in Table 1. Percentage difference for Cs-137 and Cf-252 were found to be $2.0 \%$ and $6.5 \%$ respectively meanwhile percentage difference for $\mathrm{Am}-\mathrm{Be}$ were within $1 \%-37 \%$.

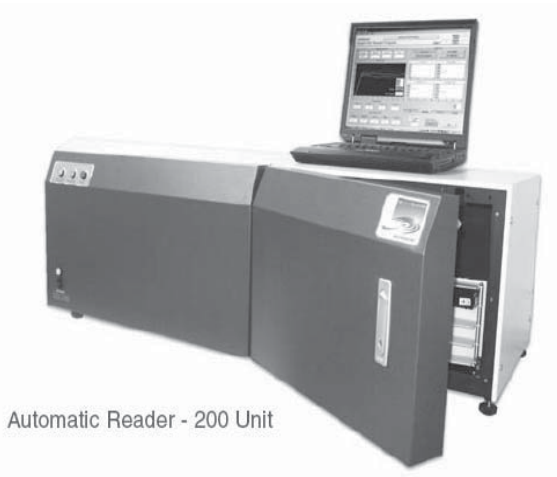

Fig. 3200 desk top InLight Reader Model.

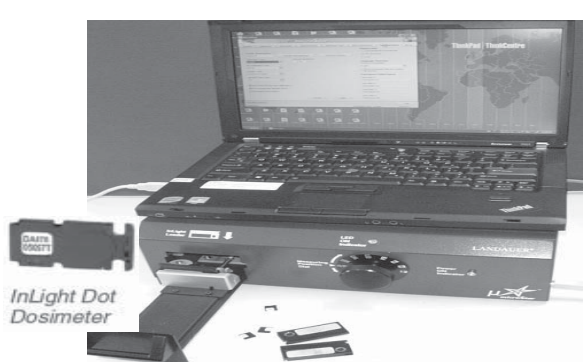

Fig. 4 Mobile reader (Microstar) and Nano dot.

Table 1. Percentage difference results of calculated and delivered dose from PTB.

\begin{tabular}{cccc}
\hline $\begin{array}{c}\text { Radiation } \\
\text { Field. }\end{array}$ & $\begin{array}{c}\text { Delivered } \\
\text { Dose } \\
(\mathrm{mSv})\end{array}$ & $\begin{array}{c}\text { Calculated } \\
\text { dose } \\
(\mathrm{mSv})\end{array}$ & $\begin{array}{c}\% \\
\text { difference }\end{array}$ \\
\hline $\mathrm{Cs}-137$ & 2 & $1.96 \pm 0.08$ & 2.0 \\
$\mathrm{D}_{2} \mathrm{O}$ Cf-252 & 2 & $1.87 \pm 0.08$ & 6.5 \\
$\mathrm{Am}-\mathrm{Be}$ & 1 & $1.37 \pm 0.14$ & 37 \\
$\mathrm{Am}-\mathrm{Be}$ & 2 & $2.23 \pm 0.43$ & 11.5 \\
$\mathrm{Am}-\mathrm{Be}$ & 3 & $3.29 \pm 0.41$ & 7.3 \\
$\mathrm{Am}-\mathrm{Be}$ & 4 & $4.04 \pm 0.11$ & 1 \\
\hline
\end{tabular}

In Figure 5, the Calibration graph between Am-Be neutron dose from software calculation and PSDL delivered dose was shown. The correlation coefficient $\left(\mathrm{R}^{2}\right)$ was found to be 0.9961 .

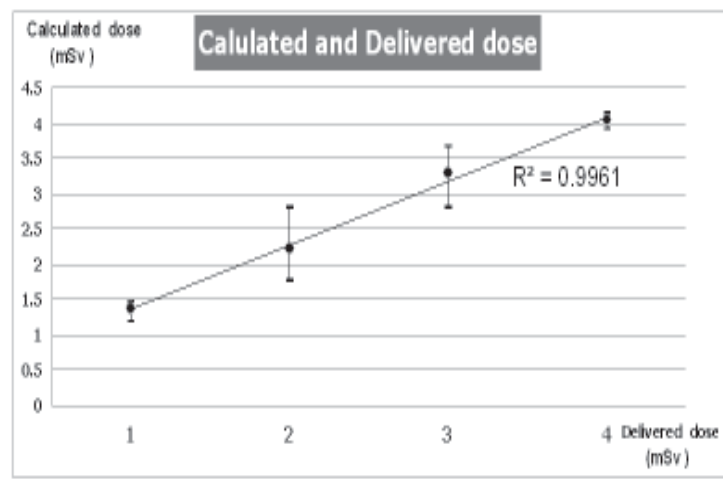

Fig. 5 Calibration graph between Am-Be neutron dose from software calculation and PSDL delivered dose.

\section{Discussion}

From the comparison results using the built-in correction factors, percentage difference for both Cs-137 and Cf-252 were $2 \%$ and $6.5 \%$ respectively. But for Am-Be neutron source calculation which no built-in correction factor, the correction factor for the energy of $41 \mathrm{keV}$ was assumed. OSL system has an advantage feature in repeating reading so selecting energy then read and re-read with other selecting energy can be performed. The percentage difference were found to be $1 \%$ at $4 \mathrm{mSv}$ delivered dose and $37 \%$ at $1 \mathrm{mSv}$. 
As general, low dose measurement deviation is greater than high dose. The calibration curve between calculated dose and PTB delivered dose were plotted and found to be linear in the range 1-4 mSv. Those calibration curve should be used to evaluate neutron dose as all our neutron clients use Am-Be neutron source. However for another neutron source, neutron energy has to be specified to get the proper correction factor in the calculation.

In conclusion, the DMSc personal monitoring service using conventional OSL dosimeter is traceable to NIST meanwhile neutron dose evaluation was validated by comparison method with delivered PTB dose. As the individual sensitivity of the OSL were defined by the manufacturing and the calibration cards were irradiated at the same standard dosimetry laboratory, the OSL cards can be evaluated using any reader elsewhere. In the emergency case, the card can be read and re-used again because the signal remains unchanged significantly after reading and dose can be accumulated up to $10 \mathrm{~Sv}$. The residual signal from all cards were cleaned up using A-50 signal eraser machine prior to send out the cards. Due to high speed reading performance, the cards reading for base line dose prior to the shipment were also performed. By the year 2012, all of the service will be switched to OSL system.

\section{Acknowledgement}

Pictures permission and information provided by Dr. I. Kobayashi and Mr. A. Matoba from Nagase Landauer Japan are highly appreciated.

\section{References}

1) L.B.Jensen, S.W.S McKeewer, A.G.Wintle. Optically Stimulated Luminescence Dosimetry (Elsevier) (2003).ISBN 0 444506845 .

2) Landauer . Personal Dosimetry Performance Testing for InLight Dosimetry (Landauer Illinois) (2006).

3) Landauer. Landauer InLight Model 2 Dosimetry Characterization and Uncertainty for National Dosimetry by Health Canabda. (Landauer Illinois) (2006).

4) Landauer Technical Review. The InLight Dosimeter Comparison with IEC 61006. (Landauer Illinois) (2006).

5) Stanford Dosimetry. Whole Body Dose Algorithm for Landauer Inlight Basic - OSLN Dosimeter 2008. Bellingham WA U.S.A. 